\title{
NOTAS SOBRE UN FEDERALISMO RENOVADO EN MÉXICO Y SU VINCULACIÓN CON LA JUSTICIA CONSTITUCIONAL LOCAL PARA LA GARANTÍA DE LOS DERECHOS FUNDAMENTALES
}

\author{
PERSPECTIVES ABOUT A RENEWED FEDERALISM \\ IN MEXICO AND ITS CONNECTION WITH THE LOCAL \\ CONSTITUTIONAL JUSTICE FOR THE ASSURANCE \\ OF HUMAN RIGHTS
}

\author{
Enrique URIBE ARZATE* \\ Alfredo MONTES DE OCA ${ }^{* *}$
}

RESUMEN: En este trabajo, los autores abordan el estudio del federalismo a partir de su conexión con la manera en que opera la justicia constitucional local en México; después de realizar un recorrido sobre las principales perspectivas teóricas que se han construido sobre el federalismo, es clara la necesidad de redimensionar su concepción para articularlo adecuadamente con el ejercicio pleno de las potestades desde los espacios locales. De este modo, el federalismo humanista ubicará en el centro de sus afanes a los habitantes y más allá de la dualidad competencial existente entre la "Federación" y las entidades federativas, permitirá a estas últimas participar activamente en el quehacer de la justicia constitucional local y en coadyuvancia con la justicia constitucional federal, mediante el ejercicio de atribuciones de jurisdicción concurrente que permitirán la garantía de un Estado constitucional.

Palabras clave: federalismo, justicia constitucional local, entidades federativas, derechos fundamentales
ABSTRACT: In this paper, the authors address the question of federalism from its connection to the way the local constitutional justice in Mexico operates. After the main theoretical perspectives revision that have been built on federalism, it is clear the necessity to do rebuilt its concept in order to articulate it properly to the full exercise of the powers from local governments. Thus, humanistic federalism will locate in the center of his labors to the people and beyond the duality of powers between the "federation" and the local governments, will enable, the latter, to participate actively in the work of local and constitutional justice in cooperation with federal constitutional law, through the exercise of powers that will allow the concurrent jurisdiction of a Constitutional State guarantee.

Descriptors: federalism, local constitutional justice, local governments, human rights.

* Doctor en derecho por la Universidad Nacional Autónoma de México, profesorinvestigador de tiempo completo en la Facultad de Derecho de la Universidad Autónoma del Estado de México.

** Doctorante en la Facultad de Derecho de la Universidad Autónoma del Estado de México. 


\section{INTRODUCCIÓN}

La época actual ha situado al Estado-nación entre dos grandes tensiones; una que se vive al iinterior del propio Estado y es visible en los movimientos por la autonomía en las entidades federativas, ${ }^{1}$ las comunidades autónomas, ${ }^{2}$ las provincias o las regiones —-según sea el Estado en cuestión- o, cuando menos, la demanda de éstas porque se les reconozcan mayores atribuciones; la otra fuerza se experimenta hacia el exterior, materializada en la potencia irresistible de la globalización que ha ejercido un poder de atracción e ineludible integración de los Estados-nación.

En relación con esto último, así se fue gestando la Unión Europea desde sus primeros atisbos en la Comunidad Europea del Carbón y el Acero (París, 1951) y en el Tratado de la Comunidad Económica Europea (Roma, 1957); más tarde con el Tratado de la Unión Europea (Maastricht, 1992) que formalizó la existencia de ese ente metaestatal nunca antes conocido, que hoy ha promovido la democratización y porqué no, la plena vocación humanista de Europa por medio del Tratado de Lisboa (2009).

A causa de esta correlación de fuerzas tensionantes - hacia el interior y hacia el exterior- el Estado se ha visto compelido a realizar significativas modificaciones en sus modos de operación, desde la toma de decisiones hasta las más sencillas tareas administrativas. Todo esto ha significado un giro en la forma de concebir el quehacer de la res publica, pues debido a los reclamos de mayor participación de los Estados-miembros, se ha tenido la necesidad de hacer radicales replanteamientos respecto a la concep-

1 En México los gobernadores se han organizado en una instancia denominada la Conferencia de Gobernadores (Conago) que ha representado un verdadero contrapeso a las decisiones del Ejecutivo federal, particularmente en los temas atinentes al presupuesto que cada entidad federativa ha de ejercer. "La Conago impulsa el fortalecimiento de las Entidades Federativas para que contribuyan en mayor medida al desarrollo nacional, cuenten con los recursos y capacidad de respuesta a las demandas de sus comunidades. La Conago reafirma el superior compromiso de las Entidades Federativas con el Pacto Federal, con el deber de impulsar un proceso político de auténtica descentralización y el fortalecimiento del Federalismo en todos los órdenes y en todas las regiones". Tomado de http://www.conago.org.mx/Sobre/QueEs.aspx, el 14 de enero de 2011.

2 En el caso español, el debate sobre la constitucionalidad o no del Estatuto de Autonomía de Cataluña que fue conocido y resuelto por el Tribunal Constitucional, pone en evidencia estos movimientos en favor de la autonomía. Como se puede ver en el texto de la sentencia STC 031/2010, la cuestión ha planteado serios problemas en la concepción misma del Estado español. Para mayor referencia, puede revisarse la sentencia en http:// www.tribunalconstitucional.es/es/jurisprudencia/Paginas/Sentencia.aspx? cod $=9873$. 
ción del Estado mismo y, evidentemente, de sus formas de organización y operación. Además de ello, la pujanza creciente de la globalización, ha propiciado - por lo mismo-, la revisión de la categoría de lo estatal y de algunos conceptos consustanciales, a su concepción, como la soberanía, la autonomía, la división de poderes, la forma de Estado, el tipo de gobierno y otras más de parecida relevancia.

Como podemos advertir, son tiempos difíciles para el Estado tipo, como forma de organización humana, pues paulatinamente han surgido y siguen emergiendo otras formas de organización, para las que el Estado resulta innecesario y en algunos casos ineficaz o cuando menos inoperante; por ejemplo, las redes sociales en Internet; las ONG de penetración internacional; las asociaciones capaces de agrupar a ciudadanos de cualquier latitud; por supuesto las empresas transnacionales y en otro sentido, los tribunales y cortes de tipo metaestatal, donde pueden ser conocidos y resueltos asuntos que en el derecho ortodoxo definían, sin más, los tribunales domésticos, todavía hasta hoy anclados en la idea de que sus decisiones son definitivas e inatacables en razón de la cosa juzgada. ${ }^{3}$

Todas las cuestiones aquí señaladas conllevan una serie de reflexiones encaminadas al rediseño de lo estatal. Así, por ejemplo, se ha mencionado ya la pertinencia de que México adopte un gobierno de gabinete, ${ }^{4}$ donde la responsabilidad de los miembros del poder ejecutivo se materialice en controles eficaces por parte del Congreso; también se ha explorado el control de la reforma constitucional ${ }^{5}$ (hasta ahora inexistente en México) y su relación con el tribunal constitucional. Casos como los aquí referidos forman parte de la agenda que investigadores y actores políticos y sociales deben considerar para que el Estado mexicano avance hasta convertirse en un Estado constitucional. En este punto, la transparencia, la rendición de cuentas y un sistema de responsabilidades viable y eficaz, son inaplazables.

3 Sobre esta cuestión puede verse el estudio de Marinoni, Luiz Guilherme, Decisión de inconstitucionalidad y cosa juzgada, Lima, Communitas, 2008, donde el autor aborda el estudio de la problemática que se genera cuando una sentencia que declara la inconstitucionalidad de una norma puede servir para dejar sin efectos la cosa juzgada en el asunto que ha sido resuelto con base en la ley declarada inconstitucional.

4 Es paradigmático en este sentido el trabajo de Valadés, Diego, El gobierno de gabinete, México, UNAM, Instituto de Investigaciones Jurídicas, 2008.

5 Sobre esta cuestión, puede verse Carpizo, Jorge, "El Tribunal Constitucional y el control de la reforma constitucional", Boletín Mexicano de Derecho Comparado, México, núm. 125, mayo-agosto de 2009. 
En este mismo orden de ideas, una cuestión esencial que se relaciona directamente con la problemática aquí planteada, es el federalismo, pues de sus modos de operación se desprenden efectos inmediatos sobre la vida social y política. Como intentaremos demostrarlo en este trabajo, el federalismo y la manera fluida de su ejercicio, condiciona o sirve de asiento para la operación óptima de otras cuestiones como el ejercicio del poder, la praxis de las relaciones interorgánicas de tipo vertical y la garantía de los derechos de los habitantes.

En estos términos está planteado el objeto de nuestra investigación, pues resulta evidente que el contexto de la cuestión, influye decisivamente en otras materias con las que desde una perspectiva distinta podría estimarse que no existe relación alguna o al menos no directa ni con tanta influencia como nosotros la estamos planteando. En este caso, nos parece que una adecuada concepción del federalismo y un ejercicio más acorde con el respeto al papel de las entidades federativas, puede auspiciar mejores desarrollos en la vida democrática de los mexicanos y en la vivencia cotidiana de sus derechos. Las entidades federativas con capacidad de actuación y la justicia constitucional local eficaz, son irremplazables en este ingente propósito.

De este modo, al margen de la vieja discusión generada en relación con el origen del federalismo mexicano, ${ }^{6}$ vamos a ensayar un redimensionamiento del sistema federal en México, pues muchos de nuestros problemas derivan justamente de la errónea concepción que se ha construido en torno a esta forma de organización que desde luego debería servir para atender con diligencia y eficacia las cuestiones locales y regionales, y que sin embargo, ha prohijado graves problemas que van desde la disputa competencial entre los diferentes "niveles" de gobierno, hasta los más sensibles debates sobre el reconocimiento a la capacidad de actuación de las autoridades locales y municipales. ${ }^{7}$

6 Por un lado se dice que el federalismo se gestó en la diputación provincial; por el otro, se afirma que su adopción fue un trasunto del federalismo norteamericano. En otro plano, también se pone a discusión la forma y la praxis, pues se ha dicho que México tiene en su diseño el tipo de Estado federal; empero, como también se ha señalado en innumerables ocasiones, la realidad es que México está lejos de los ejercicios típicos del auténtico federalismo.

7 Al respecto podemos destacar el intento de los municipios por obtener esos espacios a partir de su asociación en la Federación Nacional de Municipios de México que es una asociación creada para trabajar en favor del municipalismo en México y propiciar el fortalecimiento de las regiones. 
A partir de este debate, en nuestro criterio, el federalismo o mejor dicho, la forma de Estado federal que México planteó en su Constitución, debe ofrecer invariable congruencia en el papel y en la praxis y estar orientado por el fin superior identificado en el bienestar de los seres humanos. Un federalismo de rostro humano puede ser una respuesta atingente a nuestra complejidad como sociedad y como Estado; en este propósito, la justicia constitucional local necesita ser revalorada e impulsada para potenciar la mejor garantía de los derechos humanos.

\section{DUALIDAD COMPETENCIAL EN LA FEDERACIÓN}

Una tesis que se ha construido en torno a la idea del Estado constitucional, establece la relación inescindible que se da entre éste y el régimen democrático que le insufla vitalidad y genera los espacios propicios para el ejercicio de los derechos fundamentales.

En este sentido, la relación-condición que se puede advertir en el punto que tratamos, se patentiza cada día en la manera que el Estado va construyendo los consensos entre las diversas manifestaciones de los habitantes. Dicho ejercicio que se plasma directamente en la correlación de fuerzas que se dan al seno del Estado, da cuenta de la relevancia que esta cuestión tiene para el Estado y evidentemente para los habitantes.

Por citar algunos ejemplos, el Estado mexicano se ha ido armando a partir de diversos ensayos que han procurado establecer las formas más aconsejables para que en un mismo espacio coexistan diversos órganos con sus competencias que muchas veces convergen o se intersectan con las de otros órganos, bien sea del mismo ámbito competencial o de otro diverso con el cual comparten el ejercicio de la potestad del Estado. Baste con señalar la corresponsabilidad que de acuerdo con el artículo 21 de la carta magna tienen tanto la Federación como las entidades federativas y los municipios, en el tema de la seguridad pública, ${ }^{8}$ para ejemplificar lo que aquí se ha dicho. El Estado mexicano, tiene diversos órganos, diferentes ámbitos competenciales y cada uno de ellos, ejerce en un espacio definido

8 En materia de seguridad pública, dice así el numeral de referencia: "La seguridad pública es una función a cargo de la Federación, el Distrito Federal, los Estados y los Municipios, que comprende la prevención de los delitos; la investigación y persecución para hacerla efectiva, así como la sanción de las infracciones administrativas, en los términos de la ley, en las respectivas competencias que esta Constitución señala”. 
sus atribuciones; o para decirlo de otra manera, cada órgano ejerce una parte de la potestad estatal comprendida como unidad y totalidad.

Esta cuestión empero, no parece del todo clara cuando la praxis de dichas atribuciones llega al extremo de enfrentar a los distintos órganos titulares de éstas. De esta problemática dan cuenta las controversias constitucionales que se tramitan ante la Suprema Corte de Justicia de la Nación y otras más que se ventilan en los órganos de control constitucional que existen en algunas entidades federativas.

Como podemos ver, el escenario aquí descrito manifiesta la realidad que vive México y que seguramente viven otros países que se han organizado con base en el modelo federal; esto es, la difícil coexistencia de dos ámbitos competenciales en cada uno de los cuales los órganos tienen atribuciones y las ejercen. Desde luego, la parte nuclear del problema no se identifica en la existencia de atribuciones en uno u otro plano competencial, sino en la colisión que no es infrecuente, entre dos órganos que pueden identificarse en el mismo plano competencial o incluso en otro diferente. ${ }^{9}$

Intentamos construir entonces una tesis que permitirá comprender al Estado federal como la forma de organización jurídico política de doble plano competencial, más que el Estado donde lo federal somete y controla al espacio de las entidades federativas. Esta misma idea nos permitirá comprender al Estado federal, no más como la relación entre el centro y la periferia, ${ }^{10}$ sino como el orden jurídico-político de doble dimensión interorgánica: la dimensión interorgánica horizontal (típica en los órga-

9 Por plano competencial nos referimos en este trabajo a lo que comúnmente se llama el ámbito federal o el ámbito local, pues nos parece que el lenguaje resulta más preciso cuando nos permite trazar dos grandes dimensiones en el tema que nos ocupa: la dimensión o plano federal y la dimensión o plano de las entidades federativas, más allá del "nivel" o "ámbito" federal o local que corresponda al órgano en cuestión, pues esto ha desembocado en la idea imprecisa de que lo federal debe primar sobre lo local y a su vez, éste último espacio, sobre el ámbito municipal.

10 "El federalismo es un sistema de gobierno que pretende la unidad y la diversidad, a partir de un gobierno común federal y de reconocidos auto gobiernos regionales autónomos, orientado a aceptar y preservar las diferentes identidades dentro de una unión política más amplia. Puede representarse mediante un continuo bipolar que oscila entre una meta centrípeta, dirigida a integrar y uniformar las condiciones de vida, y otra centrífuga, dirigida a la autonomía y heterogeneidad de dichas condiciones de vida". Matheus Inciarte, María Milagros et al., "El federalismo y sus tendencias centrífugas y centrípetas. Hacia una interpretación del federalismo descentralizado en Venezuela", Revista de Derecho, Cali, núm. 23, 2005, p. 142. 
nos "federales"), y la dimensión interorgánica vertical (que se refiere a la relación entre órganos federales y locales).

Con estas aproximaciones previas, es posible destacar la problemática que aquí abordaremos, pues ha sido una constante que en el funcionamiento del Estado (federal) mexicano, invariablemente los diseños y la organización se piensen a partir de la hegemonía del ámbito federal y siempre con prelación de los asuntos correspondientes a dicho espacio, dejando en segundo lugar a las entidades federativas. En temas como la seguridad pública, la educación, la salud, el trabajo, ${ }^{11}$ por mencionar algunas de las más relevantes para el país, el diseño y la organización atienden esta dinámica. En otras cuestiones de similar relevancia como las atinentes a la asignación del presupuesto para el gasto público, la manera de tratar la relación entre la Federación y las entidades federativas no cambia.

Es evidente que esta forma de entender y regular las cuestiones que aquí hemos expuesto, dan cuenta de un tratamiento equivocado y una comprensión errónea del sistema federal, pues en el Estado federal no hay "Federación" y Estados miembros; la Federación no es algo distinto a las entidades federativas; la Federación es la suma de los espacios locales; lo que sí existe, son distintas formas de regulación de sus competencias; es decir, hay órganos "federales" que tienen atribuciones en ciertas materias (también federales) y órganos "locales" que tienen atribuciones concretas para un determinado espacio "local". Es posible que en ciertos campos, las atribuciones de ambos órganos regulen una misma actividad, pero esto no se puede llevar al extremo de entender que las autoridades locales están supeditadas a lo que dictan las del ámbito federal. ${ }^{12}$

Esto es lo que nos ha llevado a plantear desde el uso mismo del lenguaje, un cambio en la forma de relacionar a la Federación y a las entidades federativas, pues cuando se habla de los "tres niveles de gobierno", es lógico

11 Esta hegemonía de los órganos federales es evidente de acuerdo a la competencia en esta materia. La lectura de la fracción XXXI del apartado A del artículo 123 de la Constitución Política de los Estados Unidos Mexicanos, da cuenta de esto. Al final de este apabullante listado, sólo cabe preguntarnos, ¿esto es el federalismo?

12 En 2009, la Secretaría de Salud del gobierno federal (no de la federación), dictó las medidas en materia de salud que estimó adecuadas para el caso de contingencia generado por el virus de la influenza H1N1. Por su parte, las dependencias competentes en materia de salud de las entidades federativas, ejercieron sus atribuciones coincidentes a fin de contribuir a la erradicación de dicho virus, lo cual no significa que en el ejercicio de sus facultades, estas autoridades hayan sido supeditadas a la instancia federal. 
sostener que entre esos "niveles" hay alguno que está situado por encima del otro o de los otros y que, por tanto, necesariamente debe existir una relación jerárquica.

No cabe duda que la expresión más adecuada debe tomar en consideración las atribuciones de cada órgano, las materias que se regulan y los sujetos facultados para ello. En tal sentido, la expresión "ámbitos competenciales" ayuda más en este intento epistemológico, pues es claro que con ello no se introduce ninguna relación de tipo jerárquico.

Con todo ello, todavía — según nuestro entender - es más adecuado decir que en el Estado federal hay dos planos o dimensiones competenciales, debido a que es así como se proyectan los asuntos en el Estado. La coexistencia de órganos en el espacio federal y otros más en el espacio local no implica que las dependencias de los gobiernos locales estén supeditadas a las correspondientes del gobierno federal. En tal caso, nos enfrentamos a lo que la doctrina denomina las atribuciones concurrentes ${ }^{13}$ y que no son otras que aquellas que distintos órganos de diferentes espacios competenciales pueden ejercer de manera simultánea.

En este orden de ideas, también se ha mencionado al federalismo dual y la cooperación federal, como una posibilidad de mejorar las relaciones entre Federación y Estados miembros. El primero de ellos, es decir el federalismo dual, ${ }^{14}$ consiste en determinar que aquella facultad que no esté expresamente otorgada o reservada a la Federación, queda establecida en favor a los estados federados. Por ello, se sostiene "la existencia de dos ámbitos de poder, mutuamente exclusivos y recíprocamente limitados, con

13 Miguel Covián prefiere llamarlas facultades coincidentes aduciendo lo siguiente: “...lo que se establece en nuestra constitución... es la coincidencia de facultades de los órganos federales, locales y municipales en diversas materias... En todos estos casos, actúan al mismo tiempo los tres niveles de gobierno..." Covián Andrade, Miguel, Diez estudios antidogmáticos sobre el sistema constitucional mexicano, México, CEDIP, 2009, p. 239.

14 "El concepto de federalismo dual empezó a ser popularizado por Corwin en 1934, remitiendo su origen a las tesis de Hamilton, plasmadas en los artículos 39 y 46 de El Federalista". Fernández Segado, Francisco, El federalismo en América Latina, México, Cuadernos Constitucionales México-Centroamérica, Centro de Estudios Constitucionales México-Centroamérica, Instituto de Investigaciones Jurídicas, Universidad Nacional Autónoma de México, Corte de Constitucionalidad, República de Guatemala, 2003, p. 13. 
unos gobiernos respectivos situados en un plano de absoluta igualdad en cuanto igualmente soberanos". ${ }^{15}$

Por su parte la cooperación federal, queda inmersa en lo que la doctrina conoce como federalismo cooperativo, el cual es un nuevo modelo de federalismo, que "presupone la coparticipación de poderes y funciones entre las distintas entidades de gobierno, básicamente las federales y las estatales". ${ }^{16}$ Es importante destacar que esta cooperación "no se circunscribe a la elaboración de leyes sino que, bien al contrario, se proyecta a la dirección de programas, a la planificación de actividades... en síntesis la competición cede su paso a la cooperación". ${ }^{17}$

Con estas referencias podemos identificar la forma errónea en que hasta hoy se han concebido las relaciones entre la Federación y los estados miembros. En nuestra concepción, México requiere potenciar su sistema federal de manera tal que su praxis se focalice hacia el bienestar de la población, como elemento primordial de la existencia del Estado. No podemos seguir considerando el federalismo como tensión entre ámbitos competenciales y ni siquiera como una forma de organización jurídico-política, auspiciada por la cooperación entre los distintos "niveles de gobierno".

Para concluir esta parte, solamente resta señalar que un Estado constitucional que ha apostado por el federalismo como su forma de organización jurídico-política, requiere armar y practicar un sistema de vida democrático. En este sentido, el Estado constitucional se imbrica con la forma de gobierno y ambos se enlazan y encuentran su más firme basamento en un sistema democrático capaz de alentar el desarrollo de los derechos humanos, la libertad y la participación de los ciudadanos en los asuntos del Estado.

Es congruente señalar que la dimensión vivencial de una forma de gobierno así diseñada, necesita de la participación cotidiana y permanente, recia, efectiva de las entidades federativas y de todo lo que desde sus espacios locales sean capaces de ofrecer al conjunto federal. No olvidemos que por su naturaleza, el escenario idóneo para el ejercicio de los derechos fundamentales (individuales y colectivos) es la vocación democrática del Estado. Más allá del uso reiterado y hasta abusivo de este término, no cabe duda que la democracia apunta hacia su afianzamiento en la vida de todos los días.

15 Ibidem, p. 14.

16 Ibidem, p. 24.

17 Ibidem, p. 25. 
Según nuestra concepción, el Estado federal necesita fortalecer el ejercicio de las atribuciones de las entidades federativas. Un aspecto esencial en esta parte, se vincula con la justicia constitucional local que en este trabajo se mira como el punto de partida para la protección más eficaz de los derechos humanos y al mismo tiempo, como la mejor manera de operar y hacer defendible el modelo federal.

\section{DESARROLLO DEL CONSTITUCIONALISMO LOCAL}

De acuerdo con lo que hasta aquí hemos expuesto, el escenario adecuado para la generación de las mejores condiciones de vida de los habitantes se enmarca en la necesidad de llevar a cabo una reforma en la estructura del propio Estado. Cuando nos referimos a esto, estamos aludiendo a una reforma en la manera en que se organiza y diseña el gobierno del Estado; el Estado seguirá siendo el mismo; un Estado republicano, de tipo federal, que sienta sus bases en la democracia, en la seguridad y en la igualdad jurídica. ${ }^{18}$

Sin embargo, consideramos que para los propósitos que México demanda, a fin de ubicarlo como una de las sociedades de mayor bienestar y uno de los contextos donde la vida social sea posible y deseable, creemos que es necesario llevar a cabo una reestructuración en la manera que se ejerce el poder público. Dicha cuestión, sienta sus bases y está anclada en un tema todavía más relevante; al respecto, la siguiente frase condensa todo: "No puede haber mayor tarea para el Estado mexicano que el bienestar de los habitantes"; no puede haber mayor propósito político y social que la protección de los derechos de los habitantes.

Con esta premisa podemos señalar que la protección de los derechos de los habitantes, la protección de los habitantes en sentido amplio, tiene dos grandes expresiones; por un lado, la expresión proactiva que es aquella donde el gobierno genera las mejores condiciones de vida para los habitantes; se trata pues, de una acción o de una serie de acciones en las cuales el gobierno de manera dinámica genera las mejores condiciones de vida para los habitantes.

18 Incluso podríamos agregar que el Estado mexicano se identifica en el pluralismo y en su naturaleza eminentemente laica. Según nuestro punto de vista, con esto se apuntala aún más la definición del Estado mexicano que apuesta por la construcción del mejor escenario posible para el ejercicio de las libertades de los habitantes. 
El otro escenario se refiere a un contexto reactivo; aquí, el gobierno ubica y sitúa al alcance de la mano de los habitantes los mejores escenarios y los procedimientos viables para que los derechos fundamentales de estos puedan ser debidamente protegidos a través de la actuación de los tribunales y los órganos jurisdiccionales e incluso los órganos no jurisdiccionales especializados en este campo.

Se trata pues de dos contextos:

La protección de los derechos fundamentales requiere acciones concretas del gobierno para generar los mejores escenarios y óptimas condiciones de vida; ésta es la parte proactiva que hemos mencionado. Por otro lado, requiere el diseño de instrumentos, escenarios, tribunales y procedimientos eficaces que permitan a los habitantes llevar a cabo la protección, la defensa, el alegato a favor de sus derechos fundamentales. Con estos dos escenarios, podemos estimar completa la visualización y la perspectiva sobre la protección de los derechos de los habitantes en el Estado mexicano.

La primera parte que corresponde a la dimensión proactiva queda al margen de este estudio; se trata pues de la generación de políticas públicas a favor del empleo y del bienestar social. Se trata de dos expresiones que son bastante amplias; todo lo que implica la generación de un Estado de bienestar, de un Estado social; eso implica la generación del contexto proactivo. Por lo mismo, está más allá del objeto de este estudio.

La otra parte, el escenario de tipo reactivo, demanda la construcción de escenarios propicios para hacer asequible la protección adecuada de los derechos fundamentales. Este contexto se vuelve propicio cuando la forma de organización del Estado es comprendida a cabalidad como la coexistencia de una doble dimensión competencial, donde las entidades federativas tienen una participación irreductible e irremplazable. A partir de esta concepción, la capacidad de las entidades federativas en el desarrollo del Estado mexicano, está fuera de discusión. En este caso, lo que es indispensable armar, se refiere a los modos de operación de la justicia, tanto ordinaria como constitucional, en los espacios geográfico-competenciales de las entidades federativas. 
En el caso concreto de la justicia ordinaria, todas las entidades federativas cuentan con tribunales que funcionan para las más diversas materias. ${ }^{19} \mathrm{Sin}$ embargo, por lo que hace al escenario propicio para la justicia constitucional, el Estado mexicano requiere una profunda reforma constitucional que visualice la relevancia de la justicia constitucional local y su capacidad para fortalecer el sistema federal y los ejercicios democráticos.

Como sabemos, en los últimos años, la justicia constitucional local ha tenido un notable desarrollo, tanto en la parte constitucional y legislativa de las entidades federativas, ${ }^{20}$ como en los estudios científicos que de manera profusa han abordado dicha cuestión. ${ }^{21}$

En lo referente a los modos de operación de la justicia constitucional en el Estado federal, solamente nos permitimos señalar la conveniencia de involucrar en mayor medida a las entidades federativas, pues a nuestro juicio, de ello depende el éxito y la buena marcha del modelo federal. Según nosotros, es inconcebible un federalismo donde la justicia constitucional esté centralizada y los órganos jurisdiccionales especializados de las entidades federativas ni siquiera tengan atribuciones plenas para el control de la constitucionalidad de tipo local y obviamente, menos aún, para las tareas de jurisdicción concurrente. ${ }^{22}$

19 En las entidades federativas hay tribunales en materia civil; tribunales en materia penal; en materia mercantil, familiar e incluso otros, por ejemplo, los que tienen que ver con la materia contencioso-administrativa o fiscal. Esto significa que en México, los estados libres y soberanos tienen competencia plena en lo tocante a la justicia ordinaria y por ende, en nuestra opinión, muy poco se tiene que hacer o muy poco se puede hacer todavía, adicional al escenario que existe actualmente

${ }^{20}$ Hasta abril de 2011, diecisiete entidades federativas cuentan ya con algún órgano jurisdiccional especializado en justicia constitucional.

21 Al respecto, la bibliografía se ha nutrido de manera relevante, pues cada día interesa más esta temática. De los estudios que mejor ilustran esto, podemos destacar los de Astudillo Reyes, Cesar Iván, Ensayos de justicia constitucional en cuatro ordenamientos de México: Veracruz, Coahuila, Tlaxcala y Chiapas, México, UNAM, Instituto de Investigaciones Jurídicas, 2004 y el de Samaniego Santamaría, Luis Gerardo, “Análisis de la regulación de la acción de inconstitucionalidad por omisión legislativa en México", en Ferrer Mac-Gregor y Zaldívar Lelo de Larrea, Arturo (coords.), La ciencia del derecho procesal constitucional, estudios en homenaje a Héctor Fix-Zamudio en sus cincuenta años como investigador del derecho, t. VIII., México, UNAM, Instituto de Investigaciones Jurídicas, 2008.

22 Para mayores referencias sobre esta construcción, pueden verse de nuestra autoría El sistema de justicia constitucional en México, México, Universidad Autónoma del Estado de México-Miguel Ángel Porrúa, 2006. 
En este punto, vale hacer una reflexión sobre la participación de las entidades federativas en el tema que nos ocupa. Esto es, el artículo 135 de nuestra Constitución establece la participación de "la mayoría de las legislaturas locales" en la aprobación de las reformas constitucionales; luego entonces, nos preguntamos, si las reformas o adiciones a nuestra lex fundamentalis plasman la existencia de un sistema federal indispensable para alterar el máximo ordenamiento jurídico de todos los mexicanos, ¿cuál es la razón para no establecer una participación similar de las entidades federativas en algo elemental como es la defensa de la Constitución Política de los Estados Unidos Mexicanos? ${ }^{23}$

Éste es el proceso que nuestro país ha iniciado desde los espacios locales, a fin de que los órganos jurisdiccionales de cada entidad federativa, puedan conocer y dirimir los conflictos entre órganos locales y municipales y controlar la constitucionalidad de sus normas locales de cara al imperio incuestionable que debe tener su Constitución local. La tarea que en nuestra opinión queda pendiente, concierne a la intervención que dichos órganos jurisdiccionales locales deben tener, por lo que hace a la defensa de la Constitución federal desde cada entidad federativa. Ésta es la tesis que nos permite afirmar la necesidad de transformar nuestro paradigma del control de la constitucionalidad, para atenuar el centralismo (en este campo) que en términos de nuestro derecho positivo, exige que todos los procedimientos tengan la última decisión en la Suprema Corte de Justicia de la Nación y en el Tribunal Electoral del Poder Judicial de la Federación.

En un sistema federal, la Federación somos todos. La potestad pertenece a todas las entidades federativas y la justicia constitucional debe empezar en la dimensión local.

\section{EL FEDERALISMO HUMANISTA}

En la proyección epistemológica que nos ocupa, no se puede tener una visión completa si el federalismo sólo abarca las cuestiones atinentes al

23 Nos parece que así como los Estados libres y soberanos participan en el proceso de reforma constitucional, del mismo modo deberían tener atribuciones para tomar parte en la defensa de nuestra carta magna; esto se traduciría en un genuino sistema "federal" de control de la constitucionalidad; esto es, en un sistema de justicia constitucional de jurisdicción dual o concurrente, capaz de verificar el control de la constitucionalidad de actos y normas, desde los espacios de las entidades federativas. 
territorio o a las relaciones entre los niveles de gobierno. Lo federal en el Estado federal, es mucho más que relaciones competenciales interorgánicas, con todo y lo que estas representan para la vida y el desarrollo de la res pública. Lo federal debe estimarse como una manera de hacer que las diferencias entre las entidades federativas y las regiones que hay en el país, abonen con su riqueza a favor de la naturaleza plural y diversa del Estado mexicano. A fin de cuentas, México es la suma de todos esos espacios y en cada uno de ellos, lo más valioso son los seres humanos.

Es oportuno señalar que para operar este cambio del federalismo de tipo organicista al federalismo humanista, debemos considerar dos aspectos; uno de naturaleza organizacional y otro referente al bienestar. El primero de ellos, se refiere propiamente a la organización del Estado; se trata de hacer que el modelo de tipo federal sirva para arribar al segundo momento que se debe materializar en proporcionar bienestar a la población (segundo aspecto de transición).

De ahí que "la plataforma legitimante de tal relación de colaboración es un esquema de federalismo de concertación (o convergencia) y participativo, que permita una vinculación equilibrada entre las instancias que forman la estructura federal y viabilice una alternativa de desarrollo y crecimiento integrado ad intra y ad extra". ${ }^{24}$

Esta concertación se hace posible por medio de la descentralización mediante la cual el poder central reconoce en los estados miembros de la Federación, la capacidad para ejercer todas aquellas atribuciones, competencias y facultades que sean necesarias para el desarrollo y crecimiento de cada entidad federativa. Como consecuencia de lo anterior, cada región puede detonar el crecimiento y desarrollo — según sus condiciones y características - y contribuir de este modo al progreso de la "Federación" entendida como la suma de todas y cada una de las entidades federativas.

En concordancia con lo anterior, se señalan tres expresiones que permiten dar dirección a la transformación que se plantea, y son: "en la primera se enfatizan los ejes administrativo y económico, para disminuir el poder del gobierno central en la vigencia de las normas reguladoras y la participación

24 Bazán, Víctor, "La integración supranacional y el federalismo en interacción: perspectivas y desafíos", Boletín Mexicano de Derecho Comparado, vol. XLII, núm. 124, enero-abril 2009, México, UNAM, p. 64. 
del capital privado en las actividades públicas rentables que se privatizan". ${ }^{25}$ Así, el gobierno central, pierde en forma paulatina el cúmulo excesivo de atribuciones y competencias, dejando gran parte de las mismas en manos de las entidades federativas.

En la segunda vertiente: "se busca darle mayor poder a la población en la participación tanto de la gestión de los recursos, como en su producción, distribución y consumo". ${ }^{26}$ En el eje político, relativo a la tercera expresión, "se enfatiza el fortalecimiento de la democracia participativa, directa, estructurada y vinculante". ${ }^{27}$

Como podemos advertir, esta última parte del proceso en análisis, da cuenta de la relevancia que para el federalismo tienen la democracia y la participación de los ciudadanos en su práctica cotidiana. De este modo, se hace evidente la necesidad de que la población participe activamente en la toma de decisiones que afectan directamente al Estado. Por un lado, se encarga de determinar el modo de obtención, reparto y utilización de los recursos con los que cuenta el país para su sostenimiento; por el otro, se pretende que el elemento humano del Estado, viva los ejercicios democráticos como ese plebiscito de todos los días a que se refería Renán. Es hora ya de creer que principios como la soberanía y la democracia se pueden practicar desde las entidades federativas.

Sin embargo, es conveniente apuntar que el eje político no sólo se refiere a procesos electorales, sino también a los demás instrumentos y ejercicios que hacen posible la democracia plena. En este sentido, podemos hacer alusión a las formas en que la población tiene acceso a la administración del Estado, vía la transparencia y rendición de cuentas; a su participación más directa e inmediata en los procesos para la construcción de consensos de tipo legislativo o político por vía del referéndum o el plebiscito; a la intervención de los ciudadanos en el control del poder y su capacidad para revocar el mandato de sus gobernantes; por supuesto, a la esencial capacidad de los ciudadanos para exigir que sus derechos fundamentales sean garantizados plenamente por el poder público.

25 Di Paula, Jorge, “Gobernanza local en la política socio-habitacional”, Revista Invi, Chile, Universidad de Chile, número 057, año/vol. 21, agosto 2006, p. 80, disponible en: http://revistainvi.uchile.cl/ojs3/index.php/INVI/article/view/304/277, ISSN: 0718-1299.

26 Ibidem, p. 81

27 Idem. 
Este proceso que México debe iniciar a la brevedad, se tiene que desarrollar con base en los siguientes criterios:

- Subsidiariedad: significa que el nivel inferior tenga preeminencia sobre el superior por la cercanía con los problemas de la gente. Lo general se deduce de lo particular.

- Solidaridad: donde el nivel superior se oriente a equilibrar las asimetrías de la subsidiariedad, buscando redistribuir la riqueza generada en el nivel inferior.

- Concurrencia: que permita articular políticas sectoriales y territoriales.

- Flexibilidad: que facilite la adecuación a las potencialidades y debilidades de los diferentes niveles inferiores. ${ }^{28}$

Lo que se pretende lograr con el redimensionamiento del modelo federal en México, es que el "proceso de aproximación entre gobernantes y gobernados implique un desarrollo en la consideración de las necesidades y potencialidades de estos últimos, a modo de aumentar su incidencia en el mejoramiento de su calidad de vida". ${ }^{29}$ De esta forma, será posible cumplir con el fin último del Estado que consistente en procurar el bienestar de la población.

Al ubicar en el centro de todos los afanes del Estado al ser humano, el federalismo humanista debe velar por el respeto irrestricto de los derechos fundamentales. Por ello, si se pretende articular esta tendencia del federalismo, primero se debe hacer una revisión acuciosa de la legislación vigente en el Estado, a fin de asegurarse de que todos los derechos fundamentales reconocidos por éste y por el orden jurídico internacional, se encuentren completamente garantizados por el orden constitucional. Si el federalismo humanista permite colocar en su seno al hombre, es su deber garantizar un estado de bienestar infranqueable y capaz de resistir los embates de cualquier centro de poder, público o privado. El Estado tiene que ser por ende, eso que Heller llamaba "el poder normalmente más fuerte dentro de su territorio".

México tiene que asumir este papel preponderante en la cuestión que nos ocupa. Los procesos de conversión de nuestro modelo federal, no deben perder de vista que en el centro de todos estos propósitos están situados los

28 Idem.

29 Ibidem, p. 84. 
seres humanos. Si la Constitución y el poder del Estado no son capaces de garantizar los derechos de los habitantes y auspiciar su bienestar, entonces nos parece que la brújula apunta en otra dirección.

\section{NOTAS PROSPECTIVAS SOBRE LA CUESTIÓN}

Hemos anotado a lo largo de este trabajo, una serie de reflexiones que bordan sobre el deber ser del Estado y su compromiso inalienable con los habitantes. Como aspecto central de esta discusión, hemos destacado la importancia que tiene la comprensión adecuada del federalismo y sus repercusiones en la vida cotidiana, tanto para los órganos del Estado como para los habitantes.

En este hilo argumentativo, nuestra construcción epistemológica ha permitido engarzar algunas ideas centrales que van de la concepción del Estado federal hasta las condiciones y exigencias para operar eso que hemos llamado el redimensionamiento del federalismo y su concepción como un federalismo humanista. En este orden de ideas, es pertinente realizar algunas anotaciones sobre los posibles desarrollos futuros en este campo, a fin de escudriñar cuál puede ser la materialización de esta cuestión en México.

La pregunta concreta es la siguiente: ¿qué podemos hacer en México para lograr que el "sistema federal" sea en verdad federal y permita garantizar adecuadamente los derechos fundamentales de los habitantes? Según nuestra concepción, tenemos que hacer dos cosas:

a) redimensionar el sistema federal y construir el federalismo humanista por la vía del reconocimiento de que el modelo federal nace en las entidades federativas.

b) establecer un sistema de justicia constitucional que permita la intervención de las entidades federativas en los procesos constitucionales y garantice los derechos fundamentales de los habitantes.

Como se puede colegir de esto, es preciso generar los escenarios, procedimientos e instrumentos para la protección específica de los derechos de los habitantes, $\mathrm{y}$, por otra parte, como una expresión preliminar, debemos establecer los procedimientos que nos sirvan para regular el ejercicio del 
poder y en caso de abuso, para poder sancionar con eficacia a los responsables de dichas extralimitaciones.

Visto así, diremos que en primer término, México requiere una profunda reforma constitucional en el ejercicio del poder público; concretamente en las maneras en que el poder es ejercido y con una cuidadosa regulación de los mecanismos para su medida y control. La construcción de un adecuado sistema de responsabilidades es una cuestión fundamental.

Requerimos también, contar con procedimientos que nos sirvan para garantizar a los habitantes que sus derechos esenciales serán respetados de manera invariable y en todo momento. En el primer caso, el ejercicio del poder y la reforma sobre el ejercicio del poder requiere una revisión completa, integral de cuáles son los mecanismos que tenemos que utilizar para regular el ejercicio del poder, evitar los excesos y las invasiones competenciales, evitar también una cuestión que resulta esencial y no menos problemática y es la atinente al vacío de poder.

En segundo lugar, será necesario diseñar los procedimientos que sirvan para poder garantizar a los habitantes el respeto invariable, eficaz, a sus derechos fundamentales. La revisión en este caso tendrá que tomar en consideración a los órganos que actualmente existen y las instituciones que actualmente tenemos para poder realizar esta tarea. Para ello, tenemos que recomponer, reestructurar, el sistema de justicia constitucional local.

Toda vez que la protección de los derechos fundamentales se ha federalizado, porque desde la vía jurisdiccional solamente el juicio de amparo permite contar con un medio de protección eficaz, es necesario revisar el contexto más amplio, no sólo del ejercicio del poder, sus procedimientos, escenarios y mecanismos, la regulación inherente al mismo, sino además los procedimientos que actualmente existen - jurisdiccionales y no jurisdiccionales - para la protección y defensa de los derechos de los habitantes.

Como hemos señalado, no hay propósito político de mayor peso, de mayor presencia y contundencia que el respeto y la garantía de los derechos de los habitantes. El bienestar de los habitantes, la generación de un Estado de bienestar, de un Estado social, de un Estado social y democrático, de un Estado social constitucionalmente regulado y constitucionalmente garantizado, es el fin supremo del Estado.

Dicho propósito puede ser tenido incluso como instrumento para la medición de las condiciones de igualdad entre los habitantes, pues para 
los mexicanos de cualquier estrato social o condición, sin importar ideologías ni ubicación geográfica ni política, todos sin distingo, queremos que nuestros derechos fundamentales cuenten con el respaldo eficaz del Estado. Visto así, cualquier criterio para la diferenciación entre los habitantes, aminora su impacto cuando la baza de este propósito es la garantía de los derechos fundamentales.

Necesitamos pues una reforma del Estado general, amplia, integral que sitúe las acciones inmediatas en la parte esencial de esta cuestión que son justamente las entidades federativas. En este contexto, la justicia constitucional local tiene que ser vista como instrumento valioso, irremplazable para llevar a cabo dichas tareas que redundarán en un estado de bienestar para los habitantes del Estado de bienestar a que aspira el Estado federal mexicano.

Al menos para el caso de estudio que es México, los modos de operación de dicho modelo no son los más aconsejables, pues estamos lastrados por la idea de que el Estado federal se arma con elementos que actúan supeditados al nivel federal.

Lo cierto es que los graves problemas que nos agobian desde hace algún tiempo - como las crisis económicas recurrentes y el desempleo-a los que se han sumado otros de mayor impacto - como la inseguridad y el narcotráfico-, no pueden ser abordados con visos de eficacia, si todo se quiere atender y mirar desde la atalaya de las instancias federales, lejos de la realidad compleja y diversa que cada problema tiene in situ.

Hemos señalado reiteradamente que México necesita armar un nuevo diseño federal. Toda vez que el Estado federal no es sino la suma de los espacios locales, creemos que las entidades federativas deben asumir su rol protagónico en la praxis del federalismo y superar la errónea percepción de que el federalismo significa niveles de gobierno y estratificación competencial.

Además de ello, debemos valorar adecuadamente el peso específico que la justicia constitucional local tiene en la generación de escenarios propicios para la protección de los derechos de los habitantes.

\section{A MODO DE CONCLUSIÓN}

Con estos argumentos, el constructo teórico que podemos establecer se enlaza así: 
Sociedad $\rightarrow$ entidades federativas $\rightarrow$ ámbitos competenciales $\rightarrow$ federalismo humanista $\rightarrow$ justicia constitucional local $\rightarrow$ garantía de los derechos fundamentales $\rightarrow$ bienestar de los habitantes $\rightarrow$ Estado constitucional

La explicación de todo esto no puede ser más sencilla. En el flujo que hemos establecido, es evidente que cada fase constituye un momento invaluable en el proceso de construcción del Estado constitucional que debe ser alimentado con todas estas condiciones.

En el caso específico del Estado mexicano, su arribo a la dimensión de Estado constitucional, no puede lograrse al margen de las consideraciones sobre su diseño de tipo federal. Por ello, la presencia de las entidades federativas en todos los ámbitos de la vida cotidiana, no puede pasarse por alto ni ser tenidas como un asunto menor o irrelevante, pues en su praxis subyace la esencia de nuestro federalismo.

En este orden de ideas, las tareas encargadas a los órganos jurisdiccionales de las entidades federativas, especializados en materia de control de la constitucionalidad, deben ocupar un lugar preponderante en el accionar de los Tribunales de justicia locales, toda vez que en ellos reside la verdadera fuerza del federalismo y su vivencia desde los espacios locales.

Como lo señalamos al principio, el Estado sufre los embates de dos fuerzas tensionantes; es inconcuso que la era de la globalización, ha traído consigo una grave crisis de la era estatal.30 Por ello, tenemos apremio por generar una nueva forma de operar el modelo federal que dará solidez y certidumbre al Estado mexicano. Además de las reformas y el cambio de paradigma del modelo federal, debemos considerar otras formas de operación de lo estatal. Por ejemplo, en el uso de conceptos como gobernanza, el cual implica algunas notas distintivas como las siguientes:

- La no existencia de un centro jerárquico capaz de fijar procesos de gobierno de forma monopólica. En positivo: la estructura multinodal de la red y la determinación relacional de procesos y de resultados.

- La interdependencia: no se trata sólo de pluralismo, de más actores; se trata sobre todo de dependencias mutuas (heterarquías) en-

30 Rojo Salgado, Argimiro, "Globalización, integración mundial y federalismo", Revista de Estudios Políticos (Nueva Época), España, núm. 109, 2000, julio-septiembre, p. 30, disponible en: http://www.cepc.es/rap/Publicaciones/Revistas/3/REPNE_109_031.pdf. 
tre estos actores en el momento de resolver problemas, perseguir objetivos y conseguir ciertos resultados.

- Una cierta institucionalización, en el sentido menos estructural del término. Es decir, la existencia de unas interacciones más o menos sostenidas con algún nivel de estabilidad. ${ }^{31}$

Es claro que el Estado mexicano necesita estos modos de operación de lo público en todos sus espacios. Esta regulación debe tener como bastión el federalismo humanista que en la dimensión propuesta será capaz de dar cauce a los ejercicios constitucionales de tipo local, más allá del discurso que señala la existencia de Estados libres y soberanos y de sus respectivas Constituciones locales, hasta ahora sometidos al "nivel federal" que en términos directos y llanos, no tiene más potestad sobre las entidades federativas que sus atribuciones constitucionalmente reguladas.

México necesita un federalismo humanista que garantice las múltiples interacciones entre los espacios locales y regionales; que permita la consecución de los objetivos más apremiantes para cada entidad federativa y haga más fuerte al Estado federal en la misma medida que sus espacios locales puedan ejercer su libertad y sus atribuciones.

Sólo por citar un ejemplo, podemos mencionar la pertinencia de que en cada entidad federativa la protección de los derechos fundamentales (individuales y colectivos) pueda tramitarse mediante un procedimiento jurisdiccional similar a un juicio de amparo local. Con independencia de la denominación que se le dé, lo relevante se ubica en la posibilidad de que los habitantes puedan tener al alcance de la mano, la incoación de un procedimiento de tal naturaleza en los propios tribunales locales. Recordemos que así nació el juicio de amparo en la Constitución de Yucatán en 1841; ¿será aconsejable regresar al modelo original?

Por lo pronto, según nuestra perspectiva, el sistema de justicia constitucional de México tiene que ser difuso, dual y concurrente.

El carácter difuso está planteado y previsto en el segundo párrafo del artículo 133 de la Constitución Política de los Estados Unidos Mexicanos. Nos parece que una tarea inseparable de la naturaleza misma del ejercicio

31 Blanco, Ismael y Gomà, Ricard, "Del gobierno a la gobernanza: oportunidades y retos de un nuevo paradigma", Politika Revista de Ciencias Sociales, 2006, num. 2, diciembre, p. 17, disponible en: http://bilbaoglocal.org/politika_rcs/bi/eng/politika.org. es_n2_blanco-goma.pdf, ISSN: 1885-9488. 
del poder público, tiene que ver con la permanente verificación del acuerdo normativo entre las leyes ordinarias y la Constitución. Esta obligación debe abarcar a todo aquél que ejerza un espacio de la potestad del Estado; por tanto, la constatación de la constitucionalidad de los ordenamientos con base en los cuales la actuación de un servidor público tiene fundamento, debe ser una tarea primigenia de los órganos del Estado.

En cuanto a la naturaleza dual, podemos referirnos a la existencia de dos ámbitos competenciales para el control de la constitucionalidad que son el federal y los de las entidades federativas. Un Estado federal que cuenta con entidades federativas y las respectivas Constituciones en cada una de ellas, tiene que propiciar el funcionamiento de esos dos órdenes normativocompetenciales para llevar a cabo el control de la constitucionalidad de normas y actos en la dimensión federal y similares esfuerzos en los ámbitos de cada entidad federativa. A menos que el federalismo sea una ficción y las entidades federativas meros espacios administrativos carentes de autonomía y capacidad para la organización política, los órganos jurisdiccionales de control constitucional local, serán igualmente fatuos ensayos jurídicos.

En relación con el carácter concurrente a que nos hemos referido, nos parece incontestable que las entidades federativas deben incidir mediante el accionar de sus órganos de control constitucional local, en la defensa y protección de los contenidos esenciales ${ }^{32}$ de la carta magna. En su carácter de miembros del pacto federal o para decirlo técnicamente, en su carácter de entidades federativas que forman y conforman un Estado federal, todas ellas deben participar desde sus espacios competenciales en la defensa de los principios constitucionales que han permitido configurar un Estado federal que aspira a convertirse en un Estado constitucional y democrático.

En el mismo orden de ideas, podemos instrumentar el control constitucional dual o concurrente para que la defensa de la carta magna pueda hacerse desde cada entidad federativa. Nos parece que es tiempo ya de que los órganos jurisdiccionales locales especializados en justicia constitucional, tomen parte activa en la protección y garantía de los principios constitucionales plasmados en la carta magna.

32 Estos contenidos esenciales o principios constitucionales, son lo que se conoce como las decisiones políticas fundamentales. México, no podría concebirse fuera del federalismo, la división de poderes, la preeminencia del poder temporal sobre las iglesias, ni al margen de los derechos fundamentales y sus garantías. 
En la parte nuclear de todos estos afanes, se sitúan los derechos y libertades fundamentales. Pensar en este tema, nos lleva hasta la formulación de ideas más atrevidas que las imaginadas para la mera proyección simétrica de la relación Federación-entidades federativas. En este caso, los aspectos económico, fiscal, político y social que conforman la columna vertebral de la cuestión, dan paso a un afán de mayores dimensiones y no es otro que la garantía plena de los derechos de los habitantes a partir de la capacidad del Estado constitucional federal para ejercer en cada espacio local la fuerza de la Federación mexicana.

Como podemos constatar en las exploraciones científicas más recientes, ${ }^{33}$ el aspecto de las libertades y derechos fundamentales, nos puede llevar incluso hasta el reconocimiento y regulación universal de los mismos. En una proyección de tal envergadura, la coexistencia del Estado constitucional con sus pares y con el orden jurídico internacional, nos puede llevar al reconocimiento de iguales derechos y libertades a todos y cada uno de los habitantes de la aldea global; asimismo, a crear medios de control constitucional capaces de garantizar el respeto y la observancia de estas prerrogativas en cualquier lugar donde las personas se encuentren.

El federalismo humanista es apenas una primera aproximación a este nuevo escenario mundial, donde la constitucionalización del orden jurídico internacional, puede abonar igualmente en este propósito de renovación de la forma de organización del Estado federal, así como de los paradigmas del derecho y de la garantía de los derechos fundamentales.

Podemos decir entonces que la justicia constitucional local es un presupuesto inmanente al sistema federal y un elemento indispensable para la protección más adecuada de los derechos de los habitantes. En la medida que esta forma de operación del Estado federal pueda ensayar sus mejores opciones - por medio de la participación de las entidades federativas en esta materia-, podremos avanzar en el mejoramiento de nuestro sistema federal y, al mismo tiempo, en la consolidación de la protección constitucional desde las entidades federativas.

33 Véase Soto Reyes Garmendia, Ernesto, "Federalismo, sociedad y globalidad: los retos del porvenir", Política y Cultura, México, núm. 25, primavera de 2006, asimismo, puede consultarse Reidy, David A., "An internationalist conception of human rights", The Philosophical Forum, vol. XXXVI, núm. 4, invierno de 2005, tomado de la página http://onlinelibrary.wiley.com/doi/10.1111/j.1467-9191.2005.00210.x/pdf el 25 de abril de 2011. 
La aseveración a favor del constitucionalismo local, no puede tener un asidero más sólido que la necesaria imbricación que debe darse entre las entidades federativas y la "dimensión federal" de la potestad del Estado. A fin de cuentas, la potestad es una sola y corresponde al Estado mexicano en su conjunto; los "ámbitos competenciales" o los "niveles de gobierno" son una construcción que sólo puede justificarse en la medida que su telos esté focalizado hacia el bienestar de los habitantes.

\section{BIBLIOGRAFÍA}

ASTUDILlo ReYES, Cesar Iván, Ensayos de justicia constitucional en cuatro ordenamientos de México: Veracruz, Coahuila, Tlaxcala y Chiapas, México, UNAM, Instituto de Investigaciones Jurídicas, 2004.

BAZÁN, Víctor, "La integración supranacional y el federalismo en interacción: perspectivas y desafíos", Boletín Mexicano de Derecho Comparado, México, UNAM, vol. XLII, núm. 124, enero-abril de 2009.

BLANCO, Ismael Y GOMÀ, Ricard, "Del gobierno a la gobernanza: oportunidades y retos de un nuevo paradigma", Politika Revista de Ciencias Sociales, núm. 2, diciembre de 2006.

Di PAUlA, Jorge, "Gobernanza local en la política socio-habitacional", Revista Invi, Chile, núm. 57, año/vol. 21, agosto de 2006.

CARPIZO, Jorge, "El Tribunal Constitucional y el control de la reforma constitucional", Boletín Mexicano de Derecho Comparado, México, año XLII, núm. 125, mayo-agosto de 2009.

COVIÁN ANDRADE, Miguel, Diez estudios antidogmáticos sobre el sistema constitucional mexicano, México, CEDIP, 2009

Fernández Segado, Francisco, El federalismo en América Latina, México, UNAM-Corte de Constitucionalidad, República de Guatemala, 2003.

MARINONI, Luiz Guilherme, Decisión de inconstitucionalidad y cosa juzgada, Lima, Communitas, 2008.

MATHEus InCIARTE, María Milagros et al., "El federalismo y sus tendencias centrífugas y centrípetas. Hacia una interpretación del federalismo descentralizado en Venezuela", Revista de Derecho, Cali, núm. 23, 2005.

SAMANIEGO SANTAMARÍA, Luis Gerardo, "Análisis de la regulación de la acción de inconstitucionalidad por omisión legislativa en México", en FERRER MAC-GREGOR, Eduardo Y ZALDÍVAR LELO DE LARREA, Arturo 
(coords.), La ciencia del derecho procesal constitucional, estudios en homenaje a Héctor Fix Zamudio en sus cincuenta años como investigador del derecho, México, UNAM, Instituto de Investigaciones Jurídicas, 2008, t. VIII.

REIDY, David A., "An Internationalist Conception of Human Rights", The Philosophical Forum, vol. XXXVI, núm. 4, Winter of 2005.

RoJo SALGADO, Argimiro, "Globalización, integración mundial y federalismo", Revista de Estudios Políticos, España, núm. 109, julio-septiembre.

Soto ReYes GARMENDIA, Ernesto, "Federalismo, sociedad y globalidad: los retos del porvenir", Política y Cultura, México, núm. 25, primavera de 2006.

UriBe ARZATE, Enrique, El sistema de justicia constitucional en México, México, UAEM-Miguel Ángel Porrúa, 2006.

Valadés, Diego, El gobierno de gabinete, México, UNAM, Instituto de Investigaciones Jurídicas, 2008. 